\title{
How fast should social restrictions be eased in England as COVID-19 vaccinations are rolled out?
}

\author{
David Miles ${ }^{1}$, Adrian Heald ${ }^{2}$, and Mike Stedman ${ }^{3}$ \\ ${ }^{1}$ Imperial College London \\ ${ }^{2}$ Salford Royal Hospitals NHS Trust \\ ${ }^{3}$ Res Consortium
}

March 15, 2021

\begin{abstract}
Vaccination against the COVID-19 virus began in December 2020 in the UK and is now running at 5\% population/week. High Levels of social restrictions were implemented for the third time in January 2021 to control the second wave and resulting increases in hospitalisations and deaths. Easing those restrictions must balance multiple challenging priorities, weighing the risk of more deaths and hospitalisations against damage done to mental health, incomes and standards of living, education outcomes and provision of non-Covid-19 healthcare.

Weekly and monthly officially published values in 2020/21 were used to estimate the impact of seasonality and social restrictions on the spread of COVID-19 by age group, on the economy and healthcare services. These factors were combined with the estimated impact of vaccinations and immunity from past infections into a model that retrospectively reflected the actual numbers of reported deaths closely both in 2020 and early 2021. It was applied prospectively to the next 6 months to evaluate the impact of different speeds of easing social restrictions.

The results show vaccinations are significantly reducing the number of hospitalisations and deaths. The central estimate is that relative to a rapid easing, the avoided loss of 57,000 life years from a strategy of relatively slow easing over the next 4 months comes at a cost in terms of GDP reduction of around £0.4 million/life-year loss avoided. This is over 10 times higher than the usual limit the NHS uses for spending against Quality Adjusted Life Years (QALYs) saved. Alternative assumptions for key factors affecting give significantly different trade-offs between costs and benefits of different speeds of easing. Disruption of non-Covid-19 Healthcare provision also increases in times of higher levels of social restrictions.
\end{abstract}

In most cases, the results favour a somewhat faster easing of restrictions in England than current policy implies.

\section{Hosted file}

How fast should restrictions be eased v5 March14 Authorea.pdf available at https://authorea. com/users/333926/articles/513507-how-fast-should-social-restrictions-be-eased-inengland-as-covid-19-vaccinations-are-rolled-out 